\title{
METÁFORAS SOBRE O TEMPO E ESTILIZAÇÃO DA ESCRITA ACADÊMICA EM DIREITO: TEMPO DE CRIAÇÃO OU DE PRODUÇÃO? UM DIÁLOGO COM A LITERATURA
}

\author{
FAYGA SILVEIRA BEDÊ ${ }^{\mathbf{1}}$ \\ RAPHAElla Prado Aragão de SoUSA ${ }^{2}$
}

\begin{abstract}
RESUMO: Por meio de metalinguagem, propomos uma articulação entre a literatura e a escrita acadêmica no âmbito da pesquisa jurídica. Partimos da hipótese de que a literatura pode nos ensinar a constituir uma escrita mais autoral, por meio da mobilização de múltiplas funções da linguagem, garantindo efeitos de estilo que realçam os aspectos narrativos e argumentativos da pesquisa em Direito. Entendemos que a artesania das palavras, apreendida na escrita literária, pode emprestar aos escritos jurídicos um senso de posteridade, reafirmando-os contra as ruínas do esquecimento. Por fim, nós recorremos à marcha lenta da criação literária para questionar a azáfama dos pesquisadores em Direito, premidos pela velocidade da era digital e pelas demandas do produtivismo. Em resposta aos excessos da produção, propomos uma estética da criação.
\end{abstract}

Palavras-ChaVe: escrita literária; escrita acadêmica; autoria; tempo; produtivismo.

1 Doutora em Sociologia pela Universidade Federal do Ceará (UFC). Mestre em Direito pela Universidade Federal do Paraná (UFPR). Graduada em Direito pela Universidade Federal do Ceará (UFC). Professora do Mestrado e da Graduação em Direito do Centro Universitário Christus (UNICHRISTUS). Editora-Chefe da Revista Opinião Jurídica. Fortaleza (CE), Brasil. ORCID: https://orcid.org/o000-0001-6444-2631. CV Lattes: http://lattes.cnpq.br/1585343653527993. E-mail: bedefayga@gmail.com.

2 Mestranda em Processo e Direito ao Desenvolvimento pelo Centro Universitário Christus (UNICHRISTUS). Graduada em Direito pelo Centro Universitário Christus (UNICHRISTUS). Fortaleza (CE), Brasil. ORCID: https://orcid.org/oooo-0001-75976022. CV Lattes: http://lattes.cnpq.br/7766085884297690. E-mail: raphaellapradoaragao@gmail.com. 


\section{PRIMEIRAS APROXIMAÇÕES}

"Possa a morte arrebatar-me enquanto
penso, escrevo, leio." (Epitecto)

Todo gesto de escrita esconde um naufrágio. Todo aquele que escreve revive a esperança do náufrago que, prestes a sucumbir, lança ao desconhecido um chamado. A esperança arquetípica do escritor é que suas palavras sejam encontradas a tempo. O que nem sempre percebemos é que a própria escritura já é em si uma forma de redenção.

Pouco importa se nossas palavras seguirão o seu destino em um papel amarrotado, encalacrado em uma garrafa de vidro, ou se as verteremos na tela do ecrã, dispersando-as mundo afora pelas redes digitais: o desejo que nos anima é sempre a possibilidade do encontro. Quem escreve encontra primeiro a si ${ }^{3}$, e isso é já um livramento. Escrevemos para saber do que se trata. Ainda que partamos de um tema, cuja matéria se prefigura em nossa consciência, de modo mais ou menos elaborado, é no próprio ato da escrita, quando o fundo encontra a forma, que se consubstancia a escritura ${ }^{4}$. Forma e fundo se entretecem, num amálgama que constitui, a um só tempo, obra e autor.

Mesmo que possamos contar com um suporte muito promissor, como é o caso, por exemplo, de uma revista renomada, cuja proposta vai ao encontro de um nicho de leitores especializados, os quais formam um público-leitor previamente interessado ou predisposto, pode ser que nada aconteça. Para superarmos a incomunicabilidade, cuja ameaça latente tangencia a experiência humana, é preciso que as palavras escritas pelo autor sejam inscritas na alma do leitor, de modo que as ideias, as experiências, os sentimentos e a visão de mundo do escritor sejam vivificados pelo leitor.

3 Nesse sentido, vide o belíssimo ensaio de Prigol (2010).

4 Em seu prefácio à obra de Tzvetan Todorov, leciona Perrone-Moisés (2013, p. 10): "Forma e conteúdo são inseparáveis. Onde está o conteúdo senão na forma? Será possível uma forma verbal sem conteúdo?”. 
Esse estado de comunhão de almas, cuja chave de acesso é a leitura, é possibilitado pela potência da escritura, quando as palavras se subtraem aos limites do espaço e do tempo, reverberando em cada leitor, como se, de algum modo, ele mesmo as tivesse escrito. Essa qualidade epifânica da literatura (Castagnino, 1969) ocorre no autor, durante o processo de escrita, e se reacende no Outro, quando este, no momento da leitura, se reconhece nas palavras daquele, revestindo-se delas como se fossem suas, pois o grau de ressonância com que elas o atravessam constitui, para o leitor, uma forma de também ser salvo.

Isto é, ao salvar o autor-náufrago das ruínas do esquecimento, por meio de sua leitura vivificante, o leitor salva a si mesmo de seu próprio naufrágio, mobilizando, por meio das palavras do Outro, o grau de verdade e de beleza de que precisa para constituir seus reservatórios de sentido: “[...] para ser bom leitor é mister trazer dentro de si algo de espírito criador, pois há uma leitura criadora semelhante à criação escrita" (Castagnino, 1969, p. 51).

Mas, por ora, deixemos de lado essas questões mais abissais - do desejo de encontro que move todo gesto de escrita e do medo inexorável do autor de não fazer chegar ao leitor a sua carta de náufrago. Precisamos, antes de mais nada, arar a terra batida e esclarecer, afinal, o que pretendemos com o presente ensaio.

Por respeito intelectual ao esforço do leitor que estiver conosco pelas próximas páginas, desejamos deixar claros, desde logo, os nossos objetivos, quais sejam: (i) refletir sobre o imaginário que conforma a mentalidade do senso comum douto em relação ao padrão "correto" de escrita acadêmica em Direito; (ii) promover uma aproximação entre o registro da escrita literária e o registro da escrita acadêmica, alargando a possibilidade do uso de certas funções da linguagem ainda pouco usuais no âmbito da pesquisa jurídica; (iii) refletir sobre as condições que vêm sendo impostas à produção acadêmica, seja em razão dos influxos da era da velocidade sobre o modo como gerimos o nosso tempo, seja em razão das limitações que o paradigma produtivista pode ensejar quanto à qualidade da escrita (e da pesquisa) acadêmica produzida no âmbito jurídico.

Assumimos - por dever de coerência às ideias aqui apresentadas uma metodologia de escrita menos ortodoxa e mais rente ao gênero 
ensaístico e nos valemos tanto de pesquisa bibliográfica, como também de observação participativa e não participativa, a partir das múltiplas posições que a dinâmica da vida acadêmica nos requer, seja na condição de autores, seja como leitores, pesquisadores, avaliadores, entre outros. Por fim, traçamos um percurso hipotético-indutivo, submetendo ao debate acadêmico algumas hipóteses que elaboramos a partir de experiências pessoais e acadêmicas, vividas ou observadas.

\section{A LITERATURA ARTICULA FUNÇÕES DA LIGUAGEM QUE PODEM GARANTIR UMA ESCRITA ACADÊMICA MAIS AUTORAL PARA OS JURISTAS}

"Não fiz meu livro mais do que ele me fez." (Montaigne)

Nossa primeira hipótese de trabalho é a de que, na área de humanidades - em que narração e argumentação se imiscuem numa só tessitura -, a escrita acadêmica atingirá maior universalidade e permanência, quanto mais se aproximar das qualidades estéticas da escrita literária, devendo o autor chamar para si o dever de tratamento do texto, de burilamento das formas, de artesania das palavras, em um movimento de mútua afetação entre fundo e forma, que alça o escritor acadêmico à condição de autor.

Para efeito da distinção ora pretendida entre escritor e autor, esclareçamos o que seria um e outro. Reputamos "escritor", no âmbito da academia, aquele que apenas dá passagem a uma série de vozes, apresentando as ideias de uma infinidade de autores sem, contudo, acrescentar-lhes uma reflexão pessoal, um acréscimo que advenha de suas próprias análises e que implique um avanço efetivo para o estado da arte. Os escritores acadêmicos se sentem impelidos a sobrecarregar o seu texto por meio de um sistema de "ultrarreferenciação". Este termo foi cunhado por Rodríguez (2012) para criticar o que considera uma "semideificação" do solo teórico, muito corrente na literatura acadêmica mais ortodoxa, ainda que em prejuízo do pleno desenvolvimento das ideias de quem escreve - ou tenta escrever. 
Pessoalmente, entendemos que o escritor se converte em "autor" por meio de uma escrita mais autoral, em que ele assume o protagonismo de suas ideias ao longo do texto, trazendo outros autores na condição de interlocutores, com os quais ele interage de forma ativa, seja pelo valor agregado de suas ponderações, seja pelo modo como ele articula o seu próprio texto.

Para Rodríguez (2012), em vez de dissolvermos a nossa autoria em "teses-rígidas", excessivamente oneradas pelo dever de prestar tributo ao pensamento de um sem-número de autores, melhor seria se tomássemos de empréstimo os recursos literários da ensaística - não para nos esquivarmos ao rigor da pesquisa bibliográfica, esclarece ele, mas para constituirmos um texto no qual sobressaia a qualidade da análise de fundo combinada à expressividade literária da forma, ou seja, "a tese como ensaio".

Em sentido convergente, Geertz (2005) defende a tese de que os maiores antropólogos se tornaram cânones para a sua área de referência precisamente pelo modo como trataram o seu texto. Em outros termos, a estilização de sua narrativa traz marcas de singularidade, que constituem a própria assinatura do autor. O emprego cuidadoso de recursos estilísticos na construção de marcas pessoais ajuda a criar uma atmosfera de verossimilhança em torno da narrativa, aumentando a expressividade e o senso de verdade do texto antropológico, o que suscita nos leitores a impressão de que o antropólogo de fato "estava lá" - e que, tomando de empréstimo as suas lentes, o leitor também pode sentir-se no centro da narrativa.

Assim, de acordo com essa primeira hipótese, a escrita acadêmica deve se deixar interpelar pela literatura, superando certa tendência esquemática que pensa sobre as disciplinas de modo isolado e, por vezes, até dicotômico. Ninguém duvida de que a escrita literária e a escrita científica tenham propósitos específicos, guardando procedimentos próprios, que nunca serão plenamente coincidentes. Mas se, por um lado, é óbvio que a matéria da literatura é, no mais das vezes, ficcional, enquanto a ciência se ocupa de dar conta da realidade fática; outras conclusões muito usuais não se deveriam inferir a partir disso.

Com efeito, os valores da precisão, da objetividade e da clareza da linguagem técnica não são necessariamente obliterados pelo recurso a uma 
gama maior de funções possibilitadas pela linguagem. Muito ao contrário: o emprego controlado e consciente de certas funções da linguagem no tratamento do texto filosófico ou científico - desde que o autor evite ruídos, explicitando o sentido atribuível aos conceitos e categorias aos quais se refere - pode contribuir para realçar o caráter argumentativo do discurso, ampliando o ganho de expressividade, tanto no que concerne aos seus recursos narrativos quanto no que tange aos objetivos retóricos da argumentação.

Recuperando as lições seminais de Jakobson sobre as diversas funções da linguagem, esclarecemos que dificilmente se podem encontrar mensagens verbais que cumpram uma única função, sendo mais usual a predominância de alguma(s) dessas funções sem a necessária exclusão das demais. Senão vejamos, nas palavras do próprio linguista:

Embora um pendor [...] para o referente, uma orientação para o contexto - em suma, a chamada função referencial, "denotativa", "cognitiva” -, seja a tarefa dominante de numerosas mensagens, a participação adicional de outras funções em tais mensagens deve ser levada em conta pelo linguista atento" (Jakobson, 2010, p. 157).

Aqui chegamos à nossa segunda hipótese: o purismo das formas, nas áreas de humanas e sociais aplicadas, não só não se justifica para os fins que lhe são próprios, como também despotencializa as ferramentas de que disporíamos para enriquecer o texto acadêmico, caso incorporássemos certas funções da linguagem que ainda permanecem pouco usuais nesse território discursivo. Assim, submetemos a nossa hipótese ao debate e à reflexão da comunidade acadêmica: será que as potências criativas, reflexivas e expressivas da linguagem, reivindicáveis pelas áreas de humanidades em geral, e pelo Direito, em particular, não estariam sendo desidratadas pelas concepções puristas que pautam a escrita acadêmica própria das ciências duras?

Nesse quadrante, consideramos que a escrita acadêmica, no âmbito da pesquisa jurídica, deveria (a exemplo do que já ocorre entre autores consagrados de outras áreas de humanidades) mobilizar um leque mais amplo de recursos, a serem extraídos do catálogo de funções que a linguagem disponibiliza, a fim de constituir o seu discurso. 
Nesse sentido, a escrita acadêmica do Direito teria muito a aprender com a literatura. Com efeito, é recorrente, entre textos literários, o emprego de sucessivos deslizamentos de uma função à outra da linguagem, cujas modulações se prestam a garantir efeitos de estilo que se subsumem aos propósitos do texto.

O ensaio - entendido como um hídrido, que opera no limite entre a literatura e a escrita acadêmica - afigura-se um gênero com o qual teríamos muito a aprender. Com o uso de formas mais livres, sem que isso implique abrir mão do rigor teórico, poderíamos manejar outras funções da linguagem, tornando - pela benfazeja contaminação das formas - o nosso texto mais vivo.

Afinal, se todo conhecimento implica atividade de interpretação, viabilizada pela relação entre a subjetividade do sujeito cognoscente e a objetividade do objeto cognoscível, como nos assegura Gadamer (1997), por qual razão, no momento da escrita acadêmica, permanecemos tão refratários à ideia de assumir a presença de um sujeito como fonte emanadora da mensagem? Que estigmas tão irrefletidos nos impelem a continuar mascarando a presença de um sujeito que pesquisa, experiencia, interpreta, valora e conhece, por meio de seu intelecto, mas também pela mediação de seus sentimentos e de seus sentidos? Por que, mesmo após o advento do romantismo, da psicanálise e de tantos outros contributos teóricos do séc. XIX e do séc. XX, permanecemos, em pleno séc. XXI, tão aferrados aos grilhões do racionalismo do séc. XVII e do cientificismo do séc. XVIII? Por que continuarmos nos privando, por exemplo, da função expressiva da linguagem na produção de nossos textos acadêmicos - tal como a definiu Jakobson?

A chamada função emotiva ou "expressiva", centrada no remetente, visa a uma expressão direta da atitude de quem fala em relação àquilo de que está falando. Tende a suscitar a impressão de certa emoção, verdadeira ou simulada; por isso, o termo "função emotiva", proposto e defendido por Marty, demonstrou ser preferível a "emocional" (Jakobson, 2010, p. 157).

E que censor é esse, tão inexpugnável, que nos impede de lançar mão da função conativa da linguagem, orientada à interpelação do destinatário? Acaso não obteríamos ganhos retóricos se lembrássemos aos nossos leitores de que é com eles que estamos falando - como com você, agora? Por que 
precisamos seguir apagando as marcas da subjetividade em nosso texto, se os juízos de realidade demandam sempre a formulação de juízos de valor pelo Direito? E como tais juízos de valor haverão de se constituir, senão pelos acordos e pelas mediações de sentido entre o sujeito da escrita e o sujeito-leitor?

Por outro lado, quanto não estaremos perdendo em nos furtar à função metalinguística? Uma produção acadêmica que não se pensa a si mesma, que não reflete sobre o veículo de sua linguagem, que não examina os limites e as condições de possibilidade de sua produção discursiva precariza o seu estatuto epistemológico e retarda o seu próprio avanço como área de conhecimento.

Por fim, nós nos perguntamos o porquê de a maioria dos juristas se sentir compelida a banir de sua escritura justamente a função poética, que poderia emprestar beleza e plasticidade aos seus textos. O emprego de recursos da estilística tem colorido e realçado aspectos narrativos e argumentativos de grandes autores, nas mais variadas áreas do conhecimento, seja em filosofia, seja em diferentes vertentes das ciências humanas e sociais, criando arranjos singulares que constituem a sua marca de autoria5. No entanto, a maior parte de nós permanece alheia a esse inesgotável manancial de possibilidades. Vejamos as lições do mestre russo:

Qualquer tentativa de reduzir a esfera da função poética à poesia ou de confinar a poesia à função poética seria uma simplificação excessiva e enganadora. A função poética não é a única função da arte verbal, mas tão somente a função dominante, determinante, ao passo que, em todas as outras atividades verbais, ela funciona como um constituinte acessório, subsidiário (Jakobson, 2010, p. 163).

Assim, sempre que pertinente - e respeitadas as circunstâncias peculiares de cada produção discursiva -, seria muito proveitoso se autores e leitores de textos acadêmicos jurídicos pudessem, a exemplo do que já fazem grandes ensaístas em outras áreas, mobilizar diferentes funções da linguagem, a fim de provocar certos efeitos de estilo que em nada desabonariam o discurso acadêmico, muito antes pelo contrário.

5 Essa modalidade de escrita se dá na fronteira entre o registro literário e o registro acadêmico (assim nomeados, de forma abrangente, estudos que se prestam a uma investigação de cunho filosófico ou científico, em suas variadas vertentes). Os exemplos vão de Platão a Montaigne; até autores modernos e mesmo contemporâneos, como Barthes ou Bachelard - a lista seria invencível. 
Essa quebra de paradigmas pode ser ensejada pela maior aproximação da escrita acadêmica em relação ao modus operandi da literatura. Pois, se admitirmos, com Wittgenstein, que "Os limites da minha linguagem significam os limites do meu mundo"6, poderemos concluir que, ao nos permitirmos ampliar os limites de nossa linguagem, estaremos ampliando também os horizontes de nosso mundo.

Portanto, se desejamos mobilizar, em favor de nosso texto, maior propensão à perenidade, devemos nos atentar para as marcas de que se valem as obras literárias que transcendem os limites temporais de seus autores. Nessa esteira de pensamento, apenas a título de exemplo, o uso competente da função expressiva - quando cabível - poderia assegurar qualidade sinfrônica insuspeitável a um texto de teor acadêmico. Sobre o sinfronismo como marca da obra literária, esclarece Raúl Castagnino (1969, p. 46):

Cada vez que um homem diante de uma obra literária seja qual fôr a época em que esta nasceu - consegue emocionar-se e reviver em si os estremecimentos que comoveram o autor no instante de compô-la, opera-se o efeito do sinfronismo, flui a onda maravilhosa de sinfonia espiritual capaz de aproximar simpàticamente dois sêres, por sôbre o tempo e o espaço. A literatura é veículo sinfrônico que apaga as distâncias e as idades ao conjuro da emoção; assim entendida a criação literária, quando alcança plenitude no estético e legitimidade no humano, converte-se num lugar de encontro atemporal de duas almas sensíveis7.

Dessa forma, entendemos que não é apesar da contiguidade entre literatura e escrita acadêmica que a obra de ensaístas como Etienne de La Boétie (entre tantos outros) afirma sua vocação para a posteridade. Na verdade, supomos ser justamente em razão das qualidades estéticas de sua escritura que ela se inscreve nos anais da História. Entendemos que a sua voz, como autor, constitui-se por meio de marcas de autoria tecidas pela conjugação de diversas funções da linguagem.

Afinal, o que seria do emblemático libelo de La Boétie (2008) contra a tirania e em favor da liberdade se não fosse o poder das metáforas que o autor aciona? As imagens que ele convoca como esteio de sua tese são tão poderosas quanto desconcertantes, mostrando-nos, por exemplo, que

6 Aludimos ao aforismo 5.6 de Wittgenstein (2002, p. 114).

7 A acentuação peculiar das palavras está conforme o original. 
qualquer animal selvagem resiste até os últimos estertores, antes de se curvar ao jugo da escravidão, enquanto a maior parte dos homens aceita, sem grande resistência, sacrificar sua liberdade pessoal em face do primeiro tirano que a reivindique.

A essa altura, novas reflexões se impõem: como podemos trazer para a escrita acadêmica o sentido de ourivesaria das palavras, que é próprio da literatura, se empregamos todo o tempo de que dispomos para dar conta de leituras infindáveis? Ora pois, no contexto das pesquisas jurídicas, quase sempre escudadas apenas em pesquisa bibliográfica, não nos poderíamos dispensar desses encargos.

Essa questão nos remete ao próximo tópico.

\title{
3 TEMPO, VERTIGEM E PRODUTIVISMO ACADÊMICO: CRIAR OU PRODUZIR?
}

\author{
"Tenho em mim um atraso de nascença." \\ (Manoel de Barros) \\ "[...] já passou o tempo em que o tempo \\ não contava." \\ (Walter Benjamin)
}

Para o psicanalista Michel Schneider (1990), se é verdade que a escrita se move a partir da leitura, também pode ocorrer que alguns escritores se deixem esmagar por ela - assim, certos autores podem se sentir tentados a usar o pretexto da leitura para se furtar ao seu próprio processo de escrita, dele fugindo, deliberada ou inconscientemente, enquanto se refugiam entre seus livros, a fim de adiarem, tanto quanto possível, a hora de começar.

Afora essa atitude mais ou menos patológica de procrastinação, familiar para muitos de nós, é inegável que o tempo destinado à escrita acadêmica pode ser ameaçado pelo tempo de pesquisa que essa modalidade de escrita requer. Não por acaso, Orígenes Lessa, escritor laureado, afirmou, em entrevista, que preferia a escrita ficcional, em vez de uma escrita tributária do real, pois esta lhe demandaria grande trabalho de 
pesquisa, gerando dispêndio de tempo e de esforço ao qual ele não se dispunha (Steen, 2008).

Por outro lado, sabemos que um gênio como Flaubert, mesmo se consumindo nas mais obsessivas pesquisas acerca de todos os detalhes que envolviam o processo de escrita de seus livros, conseguiu, apesar disso, ou por isso mesmo, criar romances realistas canônicos ${ }^{8}$. Mas, e nós, os vis mortais, o que faremos para superar as tensões decorrentes do tempo cada vez mais esgarçado pela era da velocidade?

A ascensão das novas mídias, na era digital, ocasionou a supressão das barreiras geográficas que se interpunham entre nós e os outros. Resultado: demandas de toda sorte e natureza, advindas de todos os lados, conseguem nos alcançar em tempo real. A supressão do espaço desencadeou a aceleração do tempo, gerando a presentificação do presente 9 .

Outro subproduto decorrente da cibercultura é o ritmo frenético e incessante em que se dão as novas interações sociais, possibilitadas por conexões tão velozes quanto intrusivas, que usurpam grande parte do já escasso tempo que os pesquisadores deveriam destinar às suas leituras, às suas reflexões e à sua escrita: a figura do intelectual refugiado em sua torre de marfim nos parece agora uma memória fugidia.

Outrossim, os influxos da era digital instauram uma forma mais perversa e radical da "sociedade do espetáculo" descrita por Guy Debord (1997). Trata-se de um processo de subjetivação sui generis: a espetacularização propiciada pelas vitrines midiáticas está criando uma economia psíquica pautada pela exterioridade. Como uma soturna paráfrase de Pessoa, "exibir-se é preciso, viver não é preciso". Nem precisamos dizê-lo: a subjetividade sem "lado de dentro" não fecunda ideias, as esteriliza.

A um cenário complexo e multifatorial de aceleração do tempo, supressão do espaço, ubiquidade interacional e superexposição pessoal, vem se somar a emergência do produtivismo no contexto acadêmico contemporâneo. Com efeito, um dos eventos que marcaram a

8 Alguns dos trechos mais pungentes de sua copiosa correspondência foram relatados por Schneider (1990).

9 Para uma análise mais verticalizada sobre o tema, vide Benevides (1997) e Bedê (2010). 
internalização, pelo Brasil, da era "publish or perish" foi a divulgação, na década de 1980, da chamada "lista dos improdutivos da USP", quando a própria reitoria daquela universidade fez divulgar a lista dos professores que não haviam logrado publicar nenhum artigo entre 1985 e 1986. Apesar de a publicação da referida lista ter gerado muitas críticas e polêmicas acirradas, repercutindo para além dos muros da universidade, é inegável que ela surtiu forte efeito simbólico na postura de muitos professores universitários desde então (Zuin; Bianchetti, 2015).

O produtivismo instaura um mal-estar difuso e generalizado no ambiente acadêmico, resultado da dificuldade de se conciliar o desejo de produzir pesquisas de excelência qualitativa, capazes de contribuir efetivamente para a sociedade, em contrapartida à vontade de muitos pesquisadores de serem reconhecidos pelos seus pares em virtude de sua elevada produtividade (Trein; Rodrigues, 2011).

Trata-se de uma disputa entre capitais simbólicos (Grenfell et al., 2018) distintos em relação de tensão permanente e que, não raro, implicam a necessidade da tomada de posição, da parte de cada pesquisador, que precisará escolher se investirá mais esforços em qualidade ou em produtividade. Essa constante pressão por produtividade acadêmica é ainda mais perversa porque os programas aos quais se ligam os pesquisadores são avaliados quantitativamente pelo conjunto de suas publicações, em razão de mecanismos externos que não consideram as características individuais de cada pesquisador. A exigência por produção ocasiona compressão excessiva sobre os professores e sobre o corpo discente, estabelecendo como critério de progressão na carreira docente apenas o aumento da produção acadêmica, sem a correspondente avaliação da qualidade dos trabalhos (Zuin; Bianchetti, 2015).

Aqueles que focam na produtividade e na luta contra o tempo obtêm benefícios e recompensas mais imediatos e tangíveis, já que a quantidade de publicações é o principal parâmetro de avaliação para se auferir bolsas de pesquisa, prestígio e participação em alguns eventos científicos (Trein; Rodrigues, 2011).

Ou seja, o agenciamento (Zourabichvili, 2004) desses dispositivos psíquicos que forjam uma produção maquinal, ora em detrimento da qualidade das pesquisas feitas, ora em prejuízo da própria saúde dos 
pesquisadores, guarda relação direta com a natureza dos instrumentos de avaliação dos programas de pós-graduação stricto sensu, que exalta o maior número de publicações nas revistas mais bem classificadas, segundo a avaliação da Capes, independentemente da influência gerada pelo artigo. Em razão disso, para alcançar as melhores classificações, as universidades estimulam os alunos ou aplicam sanções a quem não publicar as suas pesquisas, interferindo no comportamento geral da comunidade acadêmica (Gabardo; Hachem; Hamada, 2018). Vejamos o que está em jogo:

Entre outras finalidades que poderiam ser mencionadas, hoje o Qualis é usado como: 1. Critério empregado pelas entidades de fomento à pesquisa - tais como a própria CAPES, o CNPq, as fundações estaduais - para a concessão de bolsas para professores pesquisadores (v.g. pós-doutorado no exterior; bolsa de produtividade em pesquisa; etc.) e de financiamentos a projetos de pesquisa; 2. Critério para distribuição de bolsas de iniciação científica para alunos de graduação, utilizado para avaliar a produção qualificada dos professores orientadores (inclusive aqueles desvinculados da pósgraduação) e priorizar a concessão aos docentes que possuem maior produção qualificada; 3. Critério para avaliação de candidatos em concursos públicos de professores em universidades públicas (e processos seletivos de contratação em instituições privadas), inclusive para professores que se dedicarão apenas à graduação, utilizando o Qualis para atribuir pontuação diferenciada na prova de títulos; 4. Critério para manutenção do credenciamento de professores de mestrado e doutorado, o que em instituições privadas significa, no mais das vezes, critério de manutenção do próprio emprego do docente; 5 . Critério para ingresso em processos seletivos de alunos de mestrado e doutorado, usado no momento de avaliação do currículo; 6. Critério para concessão de bolsas regulares para alunos de mestrado e doutorado; 7. Critério para concessão de bolsas de doutorado-sanduíche; 8. Critério de seleção para concursos públicos, inclusive para carreiras que não guardam relação alguma com o magistério (Gabardo; Hachem; Hamada, 2018, p. 147)

Do ponto de vista dos discentes, é bom deixarmos claro, o tempo também tem se tornado cada vez mais exíguo: às tradicionais exigências de produção de trabalhos ao fim das disciplinas cursadas, apresentação de seminários, escrita e defesa da dissertação ou da tese, vem se somando a necessidade crescente de publicação, como uma exigência adicional dos programas. Uma das dificuldades de os discentes dos PPGDs produzirem conhecimento útil e inovador em seus trabalhos finais talvez se dê em razão 
da pressão paralela para concluir artigos, submetê-los e vê-los aprovados no curto espaço de tempo até a defesa.

Logo, não nos admira que uma quantidade tão grande de implicações de reforço positivo, por um lado, e de punição, por outro, venha a pôr em risco a lógica estrutural que preside uma pesquisa focada em qualidade. É o próprio modelo de avaliação da pós-graduação brasileira que se encarrega de solapar o tempo de maturação necessário à evolução de uma pesquisa de excelência.

O atual modelo de avaliação da pós-graduação no Brasil, portanto, não é consentâneo com a demanda de tempo que a evolução do conhecimento requer. Com efeito, uma pesquisa se desenvolve aos poucos: o pesquisador vai aprimorando o seu domínio acerca de um problema, mediante observação, leitura e reflexão, procurando entender o objeto desconhecido com suporte no que já conhece (Machado Segundo, 2016).

O investigador mobiliza a sua própria experiência de vida na formulação de sua pesquisa, pois, espontaneamente, o seu passado influencia e afeta o presente. Nesse sentido, uma das complexidades da perquirição do conhecimento científico é exatamente saber controlar essa circunstância, a qual exige que o pesquisador se comporte como um artesão intelectual, que modela a sua experiência e, ao mesmo tempo, aprende a isolá-la durante a análise do objeto (Mills, 1969).

Nas áreas de humanidades e sociais aplicadas, fortemente calcadas em pesquisa bibliográfica, é fundamental que o pesquisador disponha do tempo adequado para a organização de um arquivo individual, constituído pelo conjunto de suas experiências pessoais, práticas e profissionais. Esse arquivo é composto por notas particulares, ideias, projetos, bibliografias e fragmentos de livros (Mills, 1969).

No contexto específico da área do Direito, o levantamento bibliográfico é tido como uma das etapas primordiais da pesquisa acadêmica (Wachowics; Costa, 2016), fazendo parte do armazenamento pessoal do pesquisador. Aliás, no que concerne à pesquisa jurídica, a necessidade de se constituir um bom solo teórico é ainda mais ampliada pelo fato de que a área do Direito tende a se manter relativamente alheia às 
técnicas de pesquisa de campo, cujo uso é corrente em quase todos os outros campos de saber (Borges Neto; Colácio; Bedê, 2017) ${ }^{10}$.

Por todo o exposto, seria necessário dispor do tempo adequado, a fim de que os pesquisadores da área jurídica tivessem efetivas condições de revisar o estado da arte, mapeando as fronteiras do conhecimento em sua área de especialização, de modo a elaborar uma reflexão pessoal, uma vez que, no bojo de pesquisas estritamente bibliográficas, a construção da originalidade de seu pensamento se dá, via de regra, a partir das obras preexistentes (Wachowics; Costa, 2016).

Em contrapartida, um dos subprodutos mais graves que pode decorrer da falta de tempo para o desenvolvimento adequado das pesquisas é o apelo a formas fraudulentas de se atingir a produtividade exigida. No caso de um afrouxamento moral, a falta de tempo pode encorajar aqueles que estão dispostos a tudo para maximizar as vantagens ou para evitar punições. Para quem busca o aumento de sua pontuação, a qualquer custo, o autoplágio ${ }^{11} \mathrm{e}$ até mesmo o plágio acadêmico podem parecer o caminho mais curto, quando se trata de alcançar os resultados pretendidos, representando uma solução rápida para fazer face às exigências, ainda que isso acarrete diversas consequências perniciosas dentro e fora da esfera acadêmica. É uma tentação para os iniciantes, os preguiçosos intelectuais e para quem ainda não possui estilo apropriado (Diniz; Munhoz, 2011).

Com tantas consequências negativas em jogo, consideramos ser de fundamental importância que a área do Direito se disponha a aprofundar o debate, a fim de refletir sobre parâmetros mais adequados ao estabelecimento de políticas públicas voltadas à avaliação da pós-

10 Em razão da pressa e da azáfama geral, torna-se cada vez mais desafiador desenvolver uma pesquisa bibliográfica robusta, e ainda mais improvável realizar pesquisa de campo, mas, mesmo assim, ainda temos muitos bons exemplos de estudos que partiram de uma sólida referenciação e a ultrapassaram, mediante o uso de análise de discurso, pesquisas documentais, realização de entrevistas, entre outros. Vide, em caráter ilustrativo: Gabardo; Hachem; Hamada (2018); Karam (2017); Monebhurrun; Varella (2013); Monebhurrun (2016); Trindade; Bernsts (2017).

11 Nem todos os pesquisadores têm a consciência da inadequação que o autoplágio representa, seja em termos de concorrência desleal e de consequente burla da meritocracia, no caso da disputa entre pesquisadores pelas mesmas vagas e oportunidades; seja pelo desrespeito às normas de boas práticas na pesquisa, em prejuízo de cláusulas contratuais, editalícias ou editoriais; bem como, entre outros, pelo prejuízo sistêmico para a comunidade científica, em termos de estagnação e redundância do conhecimento produzido. Para saber mais sobre autoplágio, veja-se, entre outros: Krokoscz (2012) e Volpato (2017). 
graduação, a partir de critérios que conjuguem não somente quantidade, mas também, e sobretudo, qualidade.

\section{CONSIDERAÇÕES FINAIS}

“[...] é agora, nesta contramão."

(Ana Cristina César)

Ao longo de nossas reflexões, procuramos apresentar um cenário que nos parece prejudicial para a pesquisa jurídica. Estamos vivendo em uma sociedade cada vez mais complexa, sujeita ao influxo de múltiplos fatores que interagem entre si, maximizando os danos.

Vivemos na era da velocidade, desencadeada pela ascensão das novas mídias, que suprimem as distâncias geográficas, submetendo-nos a toda sorte de demandas em tempo real. Presos a uma velocidade vertiginosa, decorrente da presentificação do presente, estamos sempre às voltas com uma complexa teia de interações sociais, que nos induzem à superexposição do eu e do Outro.

Trata-se de uma "sociedade do cansaço" (Han, 2015), despontencializada por uma economia psíquica pouco afeita à interioridade, à contemplação e à reflexão. Somos instados a nos mantermos incessantemente produtivos, em ritmo frenético e maquínico, o que nos leva a um estado de tendencial exaurimento e impotência - tal como homens-máquina, seguimos apenas funcionando.

Produzimos, publicamos, pontuamos, e assim seguiremos - até o colapso.

Ou, em lugar dessa desrazão, podemos nos reapossar de um sentido mais autêntico e transcendente, pelo qual valha a pena, de novo, refletir, meditar, criar e escrever. Afinal, se o passado já não existe mais, o futuro ainda não chegou e o presente é um instante sem espessura, que mal se insinua e já não é mais - como na pungente reflexão de Agostinho (2015) -, reconforta-nos saber que Paul Ricoeur (2010a; 2010b) não hesitou em lançar mão dos gregos, em busca de uma resposta para o nonsense da vida humana. 
De fato, Ricoeur vai colher na ideia de estrutura narrativa, desenvolvida por Aristóteles (2015), uma resposta possível para o imponderável mistério do tempo. Ao nos reconhecermos capazes de constituir as nossas experiências por meio de narrativas, passamos a poder contar a nossa própria história, dando a ela uma estrutura de sentido, não como máquinas, mas como artesãos da palavra.

Portanto, escrevemos para nos constituir como sujeitos da nossa própria história. Escrevemos para fazer de nossas vidas uma obra de arte (Foucault apud Deleuze, 1992). Escrevemos para afirmar um sentido de posteridade, indo ao encontro daqueles que ainda virão. E, se quisermos aprender a dar corda ao relógio do tempo, nada melhor que o manual de Cortázar (2015, p. 27):

Instruções para dar corda ao relógio

Lá no fundo está a morte, mas não tenha medo. Segure o relógio com uma mão, pegue com dois dedos o pino da corda, puxe-o suavemente. Agora se abre outro prazo, as árvores soltam suas folhas, os barcos correm regatas, o tempo como um leque vai se enchendo de si mesmo e dele brotam o ar, dele brotam o ar, a brisa da terra, a sombra de uma mulher, o perfume do pão.

Que mais quer, que mais quer? Amarre-o depressa ao seu pulso, deixe-o bater em liberdade, imite-o anelante. $O$ medo enferruja as âncoras, cada coisa que pôde ser alcançada e foi esquecida começa a corroer as veias do relógio, gangrenando o frio sangue de seus pequenos rubis. E lá no fundo está a morte se não corremos, e chegamos antes e compreendemos que já não tem importância (destaques nossos).

Cortázar nos devolve ao nosso ponto de partida: quem tem dado corda ao relógio do tempo em nossas pesquisas? Precisamos nos subtrair à velocidade-vertigem, criando estratégias de resistência contra a azáfama dos dias. A partir da concepção de pesquisa como "artesanato intelectual" (Mills,1969), podemos erigir um estatuto ético e estético capaz de engendrar uma nova política para a área do Direito. Nesse sentido, o fogo brando do fazer literário funciona como contraponto ao açodamento com que nos precipitamos na culinária produtivista.

Temos de debater com os nossos pares, constituintes de nossa área de conhecimento, a que valores queremos dar primazia: perenidade ou velocidade? Preferimos colecionar caracteres e publicações ou escovar 
palavras, como o poeta-arqueólogo Manoel de Barros, a extrair de cada palavra os seus sons ancestrais? ${ }^{12}$ Queremos ser escritores - apenas como quem escreve e publica - ou queremos ser autores-artesãos, donos de uma voz própria? ${ }^{13}$

A ideia de artesanato-intelectual consiste em colecionar artefatos, criando arranjos singulares, numa tessitura lenta de reflexões pessoais que - acrescentamos -, à luz da literatura, pode ser mediada pela singularidade de um texto assinado, suscitando o que ora denominamos "pesquisadorautor".

Mas, como isso seria possível, se estamos permanentemente atrasados? É que, se repensarmos o fazer do pesquisador a partir do fazer literário, estaremos instaurando um novo paradigma ético, estético e político, mediante o qual “[...] se abre outro prazo”. Não temamos repensar a lógica da linha de produção, pois "O medo enferruja as âncoras [...]". Afinal, sabemos que "Lá no fundo está a morte", mas ela só há de nos colher depois que o último leitor das nossas cartas de náufrago, enfim, se for ${ }^{14}$.

Não precisamos produzir, mas criar.

\section{REFERÊNCIAS}

Agostinho, Santo. Confissões. Trad. de J. Oliveira e A. Ambrósio de Pina. 6. ed. Rio de Janeiro: Vozes, 2015.

OZ, Amós. Rimas da vida e da morte. Companhia das Letras: São Paulo, 2008.

ARISTÓTELES. Poética. Trad. de Paulo Pinheiro. São Paulo: Editora 34, 2015 .

12 Em suas Memórias inventadas, o poeta e advogado Manoel de Barros narrou a impressão que lhe causara a primeira vez em que viu arqueólogos escovando ossos de tempos imemoriais: "Logo pensei de escovar palavras. Porque eu havia lido em algum lugar que as palavras eram conchas de clamores antigos. Eu queria ir atrás dos clamores antigos que estariam guardados dentro das palavras. Eu já sabia que as palavras possuem no corpo muitas oralidades remontadas e muitas significâncias remontadas. Eu queria então escovar as palavras para escutar o primeiro esgar de cada uma. Para escutar os primeiros sons, ainda que bígrafos" (Barros, 2018).

13 Ao longo de nosso texto, aludimos a uma ideia de autoria que, claramente, não tem o mesmo peso nem o mesmo grau de exigência que lhe atribuiu Foucault, para quem autores seriam aqueles cujas ideias e escritos são fundantes de um sistema de pensamento (Foucault, 1992).

14 Os três fragmentos textuais citados diretamente neste parágrafo haviam sido destacados agora há pouco no texto de Cortázar (2015, p. 27), por isso, optamos por não poluir a leitura, evitando indicar essa mesma circunstância a cada vez. Por outro lado, o trecho final do último período do parágrafo de encerramento da conclusão remete ao insight de Amós Oz de que só morreremos, de fato, quando vier a morrer a última pessoa capaz de se lembrar de nós (Oz, 2008). 
BARROS, Manoel de. Escovar palavras. In: BARROS, Manoel de. Memórias inventadas.

Disponível

em:

<http://contoscantoseencantos.blogspot.com/2009/02/escovar-

palavras.html >. Acesso em: 10 set. 2018.

BEDÊ, Fayga Silveira. Ciberintimidade: a escrita de si na era digital. Tese (Doutorado em Direito) - Universidade Federal do Ceará, Programa de Pósgraduação em Sociologia, Fortaleza, 2010. 223 f. Disponível em: $<$ http://www.repositorio.ufc.br/handle/riufc/17705>. Acesso em: 5 set. 2018.

BENEVIDES, Aletusya de Araújo. Espaço virtual e comunicação: novas faces de uma sociabilidade moderna. 1997. 188 f. Dissertação (Mestrado em História Social do Trabalho). - Universidade Estadual de Campinas, Campinas, 1997.

BENJAMIN, Walter. O narrador: considerações sobre a obra de Nikolai Leskov. In: BENJAMIN, Walter. Obras escolhidas: magia e técnica, arte e política - ensaios sobre literatura e história da cultura. Trad. de Sergio Paulo Rouanet. 3. ed. São Paulo: Brasiliense, 1987. p. 197-221.

BORGES NETO, José Maria de Morais; COLÁCIO, José Eduardo Barroso; BEDÊ, Fayga Silveira. A baixa incidência de pesquisa empírica e a cultura manualesca como obstáculo para o desenvolvimento do direito. Revista Direito e Desenvolvimento, João Pessoa, v. 8, n. 2, p. 247-26o, dez. 2017. Disponível em: <https://periodicos.unipe.br/index.php/direitoedesenvolvimento/article/v iew/562>. Acesso em: 30 jul. 2018.

CASTAGNINO, Raul H. Que é literatura? Natureza e função da literatura. Trad. de Luiz Aparecido Caruso. São Paulo: Mestre Jou, 1969.

CORTÁZAR, Júlio. Instruções para dar corda ao relógio. In: CORTÁZAR, Júlio. Histórias de cronópios e de famas. Trad. de Gloria Rodríguez. 3. ed. Rio de Janeiro: Best Bolso, 2015. p. 27.

DEBORD, Guy. Sociedade do espetáculo. São Paulo: Contraponto, 1997.

DELEUZE, Gilles. Conversações: 1972-1990. Trad. de Peter Pál Pelbart. Rio de Janeiro: Editora 34, 1992.

DINIZ, Debora; MUNHOZ, Ana Terra Mejia. Cópia e Pastiche: plágio na comunicação científica. Argumentum, Vitória, v.1, n. 3, p. 11-28, jan./jun. 2011.

FOUCAULT, Michel. O que é um autor? Lisboa: Vega, 1992.

GABARDO, Emerson; HACHEM, Daniel Wunder; HAMADA, Guilherme. Sistema Qualis: análise crítica da política de avaliação de periódicos científicos no Brasil. Revista do Direito, Santa Cruz do Sul, v.1, n. 54, p. 144-185, jan./abr. 2018.

GADAMER, Hans-Georg. Verdade e método I. Petrópolis, RJ: Vozes, 1997.

GEERTZ, Clifford. Obras e vidas: o antropólogo como autor. Trad. de Vera Ribeiro. 2. ed. Rio de Janeiro: UFRJ, 2005.

GRENFELL, Michel et al. In: GRENFELL, Michel (Org.). Pierre Bourdieu: conceitos fundamentais [e-book]. Trad. de Fábio Ribeiro. Petrópolis, RJ: Vozes, 2018. 
HAN, Byung-Chul. Sociedade do cansaço. Trad. de Enio Paulo Giachini. Petrópolis: Vozes, 2015.

JAKOBSON, Roman. Linguística e comunicação. Prefácio de Izidoro Blikstein. Trad. de Izidoro Blikstein e José Paulo Paes. 22. ed. São Paulo: Cultrix, 2010.

KARAM, Henriete. Questões teóricas e metodológicas do direito na literatura: um percurso analítico-interpretativo a partir do conto "Suje-se gordo!”, de Machado de Assis. Revista Direito GV, São Paulo, v. 13, n. 3, p. 827-865, set./dez. 2017. Disponível em: $<$ http://www.scielo.br/scielo.php?script=sci abstract\&pid=S1808-

24322017000300827\&lng=en\&nrm=iso\&tlng=pt>. Acesso em: 30 ago. 2018.

KROKOSCZ, Marcelo. Autoria e plágio: um guia para estudantes, professores, pesquisadores e editores. São Paulo: Atlas, 2012.

LA BOÉTIE, Etienne de. Discurso sobre a servidão voluntária ou contra o um. Cultura Brasil. Disponível em: <www.culturabrasil.pro.br/zip/boetie.pdf. $>$. Acesso em: 28 jun. 2008.

MACHADO SEGUNDO, Hugo de Brito. $O$ direito e sua ciência: uma introdução à epistemologia jurídica. São Paulo: Malheiros, 2016.

MILLS, Wright C. A imaginação sociológica. Rio de Janeiro: Zahar, 1969.

MONEBHURRUN, Nitish; VARELLA, Marcelo D. O que é uma boa tese de doutorado em Direito? Uma análise a partir da própria percepção dos programas. Revista Brasileira de Políticas Públicas, Brasília, v. 3, n. 2, p. 423-443, jul./dez. 2013.

MONEBHURRUN, Nitish. Pensando na Articulação entre a Internet como Instrumento de Pesquisa Jurídica e o Rigor Acadêmico. Revista Opinião Jurídica. Fortaleza, ano 14, n. 19, p.147-170, jul./dez. 2016. Disponível em: $<$ http://periodicos.unichristus.edu.br/index.php/opiniaojuridica/article/vi ewFile/1141/390 >. Acesso em: 20 ago. 2018.

PERRONE-MOISÉS, Leyla. Prefácio. In: TODOROV, Tzvetan. As estruturas narrativas. Tradução de Leyla Perrone-Moisés. 2. reimp. 5. ed. São Paulo: Perspectiva, 2013. p. 17-26.

PRIGOL, Valdir. Como encontrar-se e outras experiências através da leitura de textos literários. Chapecó: Argos, 2010.

RICOEUR, Paul. Tempo e narrativa: a intriga e a narrativa histórica. Trad. de Claudia Berliner. São Paulo: Martins Fontes, 2010a. v. 1.

RICOEUR, Paul. Tempo e narrativa: o tempo narrado. Trad. de Claudia Berliner. São Paulo: Martins Fontes, 2010b. v. 3.

RODRÍGUEZ, Victor Gabriel. $O$ ensaio como tese: estética e narrativa na composição do texto científico. São Paulo: Editora WMF Martins Fontes, 2012.

SCHNEIDER, Michel. Ladrões de palavras: ensaios sobre o plágio, a psicanálise e o pensamento. Trad. de Luiz Fernando P. N. Franco. Campinas: Editora da UNICAMP, 1990. (Coleção Repertórios).

STEEN, Edla Van. Viver \& escrever. 2. ed. Porto Alegre: L\&PM, 2008. v. 1. 
TREIN, Eunice; RODRIGUES, Jose. O mal-estar na Academia: produtivismo científico, o fetichismo do conhecimento-mercadoria. Revista Brasileira de Educação, Rio de Janeiro, v. 16, n. 48, p. 769-792, set./dez. 2011.

TRINDADE, André Karam; BERNSTS, Luísa Giuliani. O estudo do direito e literatura no Brasil: surgimento, evolução e expansão = The study of "law and literature" in Brazil: development, evolution and expansion. Anamorphosis - Revista Internacional de Direito e Literatura, Porto Alegre, RDL, v. 3, n. 1, p. 225-257, jan.-jun. 2017. Doi: http://dx.doi.org/10.21119/anamps.31.225-257.

VOLPATO, Gilson Luiz. Plágio e autoplágio: um desafio simples para as mentes científicas. Arquivos em Movimento, Rio de Janeiro, v. 13, n. 1, p. 24, jan./ jun. 2017.

WACHOWICZ, Marcos; COSTA, José Augusto Fontoura. Plágio acadêmico. Curitiba: Gedai Publicações, 2016.

WITTGENSTEIN, Ludwig. Tratado lógico-filosófico: investigações filosóficas. Lisboa: Fundação Calouste Gulbenkian, 2002.

ZOURABICHVILI, François. O vocabulário de Deleuze [e-book]. Trad. de André Telles. Rio de Janeiro: Centro Interdisciplinar de Estudo em Novas Tecnologias e Informação, 2004. Disponível em: $<$ http://escolanomade.org/wp-content/downloads/deleuze-vocabulariofrancois-zourabichvili.pdf/>. Acesso em: 2 set. 2018.

ZUIN, Antônio A. S.; BIANCHETTI, Lucídio. O produtivismo na era do "publique, apareça ou pereça": um equilíbrio difícil e necessário. Cadernos de Pesquisa, São Paulo, v. 45, n. 158, p. 726-75o, out./dez. 2015.

Idioma original: Português

Recebido: 02/10/18

Aceito: 28/11/18 